\title{
CHARACTERISTICS OF THE NORMAL ELECTROENCEPHALOGRAM.

\author{
II. THE EFFECT OF VARYING BLOOD SUGAR LEVELS ON \\ THE OCCIPITAL CORTICAL POTENTIALS IN ADULTS \\ DURING QUIET BREATHING ${ }^{1}$
}

\author{
By MARY A. B. BRAZIER, JACOB E. FINESINGER, AND ROBERT S. SCHWAB \\ (From the Department of Neuropsychiatry, Harvard Medical School, and the Psychiatric Department \\ and Electroencephalographic Laboratory, Massachusetts General Hospital, Boston)
}

(Received for publication August 2, 1943)

Although the rôle of blood sugar level in the slowing of cortical rhythms during hyperventilation is now very generally recognized, its effect on the electroencephalogram during quiet breathing has not been fully studied in the normal human subject.

Gibbs, Williams, and Gibbs (1), using the spectrum analyzer, concluded from a series of 4 adult normals that between extreme limits, alterations of blood sugar level have no effect on the frequency of the brain waves at normal depths of ventilation. Lennox, Gibbs, and Gibbs (2) found an upper limit of $50 \mathrm{mgm}$. for the blood sugar level to affect the electroencephalogram during normal breathing.

Davis (3) made a more extensive study on 30 normals to whom injections of insulin were given in order to lower the blood sugar below fasting levels. She found that, within 20 minutes of the injection, there was a reduction in the alpha rhythm with the appearance of 8 cycle waves. Within 30 minutes of the injection, delta waves dominated the picture. Her study was made while the subjects were breathing normally. Hoagland $(4,5)$ and his coworkers made a study of the alpha rhythm in schizophrenics at blood sugars so low as to induce loss of consciousness.

The present study is an attempt to establish the influence of blood sugar level upon the electroencephalogram at stages of unimpaired consciousness in the normal subject.

\section{METHOD}

The subjects for these experiments were all young adults, mostly college students (29 males, 16 females),

\footnotetext{
1 This study was aided by a grant from the Harrington Fund.
}

between the ages of $\mathbf{1 7}$ and 38. A brief medical history was taken and, in most cases, a brief physical examination was made before the experiment. Only those whose history indicated the absence of medical, neurological, and psychiatric disease, and whose physical examinations were within normal limits were included in the series. As a result of these brief preliminary examinations, the data on 15 individuals out of the 60 who volunteered were discarded from the series.

The routine procedure was as follows: The subject reported to the laboratory in the morning, fasting. He was asked to lie down for a period of at least 30 minutes during which time the history was taken, a brief physical examination made, and the scalp electrodes attached.

A sample of blood was drawn for the microdetermination of capillary blood sugar, and the subject was attached, by a mouth mask fitted with flutter valves, to a large spirometer with an open circuit for a period of approximately 8 minutes. He breathed outside air from the spirometer at the normal rate and depth of ventilation for a period of 2 minutes, and was then told to breathe as deeply as he could, inhaling and exhaling to the rhythm of a metronome clicking 30 times a minute. The depth of ventilation could be followed on the spirometer scale, and if the subject was not reaching the required depth for his body weight, he was urged to breathe deeper. (A study of the effects of the hyperventilation period will appear in a later paper in this series.)

After the 3-minute period of hyperventilation, the subject was told to breathe naturally, and another sample of blood was taken for the blood sugar determination, one minute after the hyperventilation period. Normal breathing was then continued for a period varying from 2 to 6 minutes, until the minute-respiratory volume was back to its base-line level.

The subject was disconnected from the spirometer and was asked to describe his subjective sensations during the test; he was then given a brief questionnaire designed to review the subjective sensations systematically.

This whole procedure was repeated within approximately 30 minutes, with the subject still in the fasting state. After another similar interval, an intravenous injection of saline was given as a control on the insulin injection to follow; this was identical in quantity and appearance with the insulin injection, and the subject was ignorant as to its nature and purpose. This control injection was to 
check on any possible rise in blood sugar, such as is sometimes found in normal persons when excited.

If, at fasting blood sugar levels, the electroencephalogram had shown no slowing of rhythm, an injection of insulin was given intravenously, the dose being calculated to give $\frac{1}{10}$ unit per $\mathrm{kgm}$. ideal body weight. Two complete experiments were then run through, one immediately after the injection, and one approximately 25 minutes after it, this being the time for the maximum effect of insulin.

After this second run under the influence of insulin, the subject was given glucose by mouth, the usual amount being 100 grams of glucose in $100 \mathrm{cc}$. of water with lemon added to make it palatable. Three further experiments were then carried through, one immediately after ingestion of glucose, one 30 minutes after, and one approximately an hour later; if the electroencephalogram did not appear normal after the second of these runs after sugar, a second

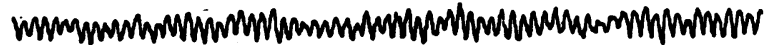

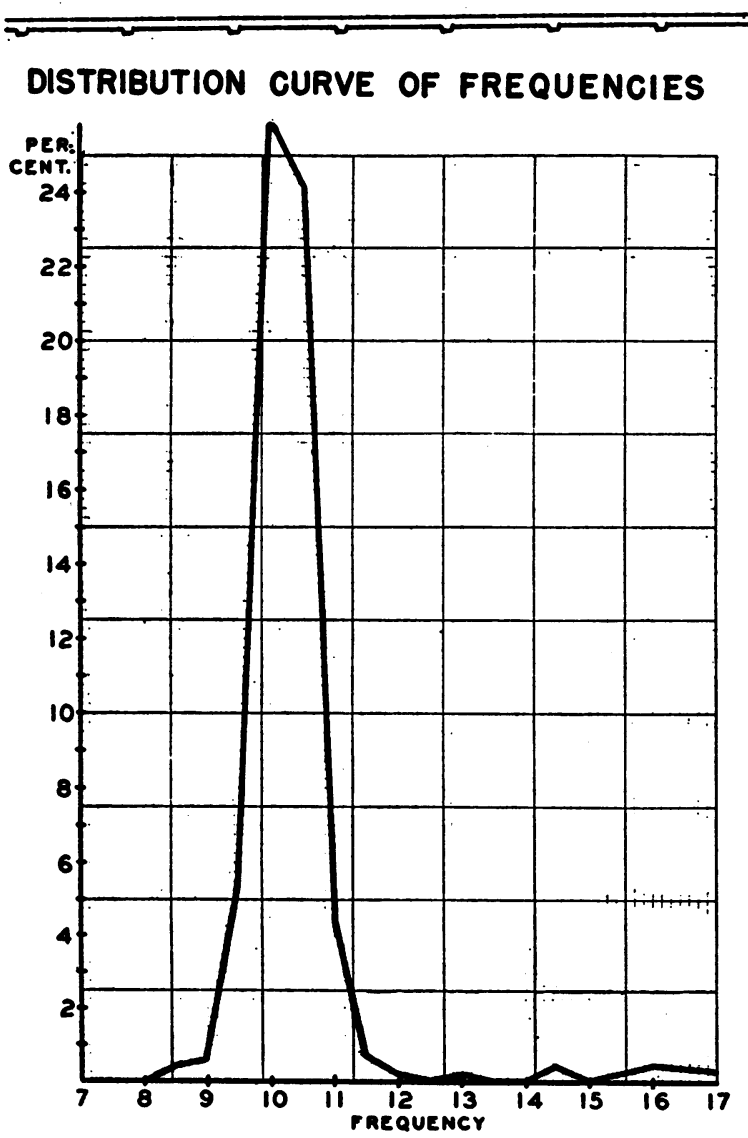

Fig. 1. Distribution Curve Compiled from a Normal Electroencephalogram Showing the Percentage of Each Frequency Present

The dominant frequency is defined as the one present in the greatest amount, i.e., at the mode of the curve (in this case, it is $\mathbf{1 0 . 0}$ cycles per second). dose of glucose would be given. At the end of the hyperventilation period of each and every electroencephalogram recording, a blood sample was taken for blood sugar determination.

In all these experiments, the technique used for recording the electroencephalogram was standardized as follows:

Six scalp electrodes were applied in the usual manner to the right and left frontal, right and left occipital, and left parietal regions, respectively. In left-handed subjects, the parietal lead was put on the right parietal region. A reference electrode was placed on one mastoid process.

For the recording, a Grass electroencephalographic apparatus was used; in all the recordings, the paper speed was $3 \mathrm{~cm}$. per second, and the pen excursion was calibrated for a sensitivity of $1 \mathrm{~cm}$. for $100 \mathrm{mV}$. All recordings were made by temote control, the subject being in a darkened room at some distance from the laboratory where the electroencephalogram was recorded.

Electroencephalographic recordings were taken throughout the whole period of each experiment, except for the minute during which the subject was being pricked for the blood sample. These blood samples were analyzed for sugar content by a modification of the Folin-Wu micro method.

\section{RESULTS}

The first characteristic of the electroencephalogram to be examined for the effect of low sugar was the dominant frequency, which is here defined as the frequency in cycles per second of the majority of the waves present.

This was determined by compiling a distribution curve of the frequencies found in the record from the occipital bipolar leads and was made by counting the percentage time occupied by waves of each frequency during the preliminary 2-minute run when the subject was breathing normally. A sample of one of these distribution curves is shown in Figure 1. The full technique, compiling these distribution curves of frequency, has been described in a previous paper (6).

The frequency at the mode of the curve, i.e., the one present in the highest amount, is the one defined as the dominant frequency. This peak may fall in the alpha range (8.0 to 13.0 cycles), in the intermediate range (13.5 to 17.5$)$, or in the beta range (18.0 or over).

Sixteen subjects with dominant frequencies in the alpha range received insulin injections, and these were examined for change in this frequency at low blood sugar levels. There were 2 to 3 recordings for each of these subjects at normal blood sugar levels (70 to $130 \mathrm{mgm}$. per 


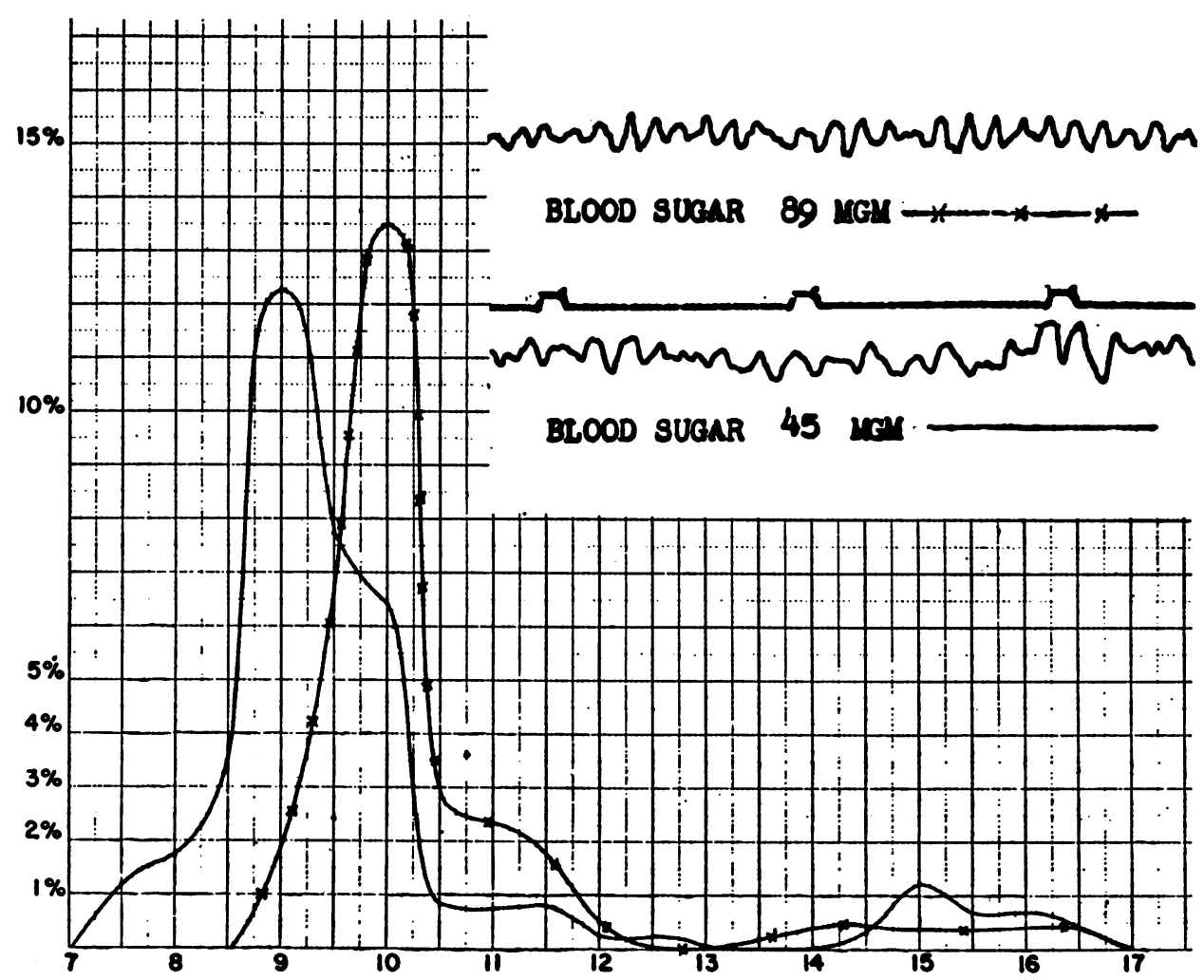

Fig. 2. Distribution Curves of the Frequencies Found in the Same Individual During a 2-minute Recording with Quiet Breathing at Two Different Blood Sugar Levels

$100 \mathrm{cc}$.$) , so that a mean could be established as a$ base-line for each individual.

When these 16 individuals are examined as a group, it is found that the mean dominant frequency after insulin is slower than at ordinary sugar levels.

The mean dominant frequency after insulin injection differs from that at normal levels by more than 4 times the standard deviation at normal levels, and this may thus be regarded as a significant difference, and it can therefore be concluded that lowering the blood sugar below

Sixteen subjects

(53 recordings)

\begin{tabular}{c|c|c|c|c}
\hline $\begin{array}{c}\text { Mean } \\
\text { dominant } \\
\text { rhythm } \\
\text { at normal } \\
\text { sugar } \\
\text { levels } \\
\begin{array}{c}\text { (70 to 130 } \\
\text { mgm.) }\end{array}\end{array}$ & $\begin{array}{c}\text { Probable } \\
\text { error } \\
\text { of this } \\
\text { mean }\end{array}$ & $\begin{array}{c}\text { Mean } \\
\text { dominant } \\
\text { rhythm } \\
20 \text { min. } \\
\text { after insulin } \\
\text { (under 70 } \\
\text { mgm. blood } \\
\text { sugar) }\end{array}$ & $\begin{array}{c}\text { Probable } \\
\text { error } \\
\text { of this } \\
\text { mean }\end{array}$ & $\begin{array}{c}\text { Difference } \\
\text { between } \\
\text { the two } \\
\text { means }\end{array}$ \\
\hline 10.56 & 0.132 & 10.00 & 0.257 & 0.56 \\
\hline
\end{tabular}

$70 \mathrm{mgm}$. per $100 \mathrm{cc}$. causes a slowing of the alpha rhythm during normal breathing. Blood sugar levels as low as $60 \mathrm{mgm}$. per $100 \mathrm{cc}$. are often found in fasting individuals who have received no insulin.

An example of the distribution curve for one individual in the series (a male aged 21) is shown in Figure 2. This diagram gives the distribution of the various frequencies found at two different blood sugar levels in the same person while breathing at a normal depth.

The plain line is the curve for the blood sugar level of $45 \mathrm{mgm}$. and the crossed line is at 85 mgm. This is a chart of the alpha and intermediate ranges of activity, and does not represent the beta frequencies.

The effect of low blood sugar on the amount of slow activity during normal breathing

Waves of a rhythm slower than the alpha range (i.e., slower than 8.0 cycles) are infrequently found in the potentials from the occiput 
in the normal subject at ordinary blood sugar levels. In this series of $\mathbf{4 5}$ subjects, no one had as much as 1 per cent of slow activity, and 35 had none at all. In no case in this series were any waves slower than 6 cycles found.

Slow activity does appear in the records of some normal subjects if the blood sugar is lowered by insulin injection. Of 18 subjects who received insulin injections, 2 developed 6 cycle waves in occipital leads while breathing normally, and 2 others showed some 7.5 cycle. The maximum percentage time slow activity (i.e., slower than 8.0 cycles) induced by insulin in any one in this series was 13.8 per cent at a blood sugar level of $45 \mathrm{mgm}$. per $100 \mathrm{cc}$.

\section{The effect of high blood sugar (above $130 \mathrm{mgm}$.) on the dominant frequency}

In this series of subjects, of those who were given glucose there were 31 (with alpha rhythms) whose blood sugars rose above $130 \mathrm{mgm}$. per 100 cc. Their mean dominant frequency was 10.31 which does not differ from the mean dominant frequency (i.e., 10.33) found at ordinary blood sugar levels.

The practical outcome of this finding, coupled with that of the slowing of the rhythm at low blood sugar levels, is that in any assessment of an electroencephalogram on a basis of frequency, one can insure against changes due to low sugar by giving the subject glucose before the test, without any fear that changes may accrue from too high blood sugar.

\section{Effect of high blood sugar on the percentage time alpha, intermediate, and beta rhythm}

At blood sugar levels above $130 \mathrm{mgm}$. per 100 cc., as induced by glucose ingestion, there is no change in the electroencephalogram from the rhythms and patterns found at normal blood sugar levels.

\section{DISCUSSION}

This quantitative study of the frequencies of cortical potentials has shown that they may be slowed in the normal adult by moderate lowering of the blood sugar level without impairment of consciousness. Since the alpha rhythm has been shown, by Hoagland's (7) experiments with pyrexia, to be directly determined by the local respiration of the cells of the cortex, any deprivation of the oxygen supply to these cells would be expected to slow the rhythm. Dextrose being the principal substrate in cerebral metabolism, hypoglycemia results in a lowering of the oxygen utilization of the brain with consequent slowing of the potentials; in animals, this has been studied by Maddock, Hawkins, and Holmes (8), and in man, by Himwich (9) who have demonstrated that on insulin injection, the progression of clinical symptoms follows the increase in cerebral arterio-venous oxygen difference and this depression of cerebral metabolism is paralleled by a decrease in alpha frequency.

A similar correlation between brain metabolism and brain potentials has been found in cretins in whom the arterial-venous oxygen differences were reduced by thyroid administration (Himwich (10)). Lindsley and Rubenstein (11) and Ross and Schwab (12) have demonstrated a direct relationship in man between the frequency of alpha waves and the total calories per hour.

Further evidence for this theory is provided by the experiments on animals of Gellhorn and Kessler (13). These authors demonstrated that the action of hypoglycemia on the brain potentials can be offset by the inhalation of pure oxygen (provided that the hypoglycemia is not so severe as to induce convulsions). Conversely, the effect of anoxia on brain potentials is greatly aggravated during insulin hypoglycemia.

\section{SUMMARY}

Blood sugar levels below $70 \mathrm{mgm}$., but insufficiently low to impair consciousness, may have the following effects on the occipital potentials of the normal electroencephalogram during quiet breathing:

Slowing of the dominant frequency.

Development of activity slower than alpha.

No change has been observed in the following characteristics:

Percentage time alpha,

Percentage time beta,

Percentage time intermediate.

High blood sugar levels, induced by the inges- 
tion of glucose (i.e., above $130 \mathrm{mgm}$. per $100 \mathrm{cc}$.), do not affect the electroencephalogram.

\section{CONCLUSION}

In the assessment of the electroencephalogram for normality, the subject should take some glucose ( 50 to 100 grams) by mouth, 30 minutes before the test, to ensure a blood sugar level above $70 \mathrm{mgm}$. per $100 \mathrm{cc}$. In this way, changes in the electroencephalogram due to low blood sugar will be avoided; raising the blood sugar above $130 \mathrm{mgm}$. per $100 \mathrm{cc}$. does not alter the electroencephalogram pattern from that at ordinary blood sugar levels.

For technical assistance in this work the authors are indebted to Miss Margaret Gray and Mrs. Frances Cooperstein.

\section{BIBLIOGRAPHY}

1. Gibbs, F. A., Williams, D., and Gibbs,-E. L., Modification of the cortical frequency spectrum by changes in $\mathrm{CO}_{2}$, blood sugar and $\mathrm{O}_{2}$. J. Neurophysiol., 1940, 3, 49.

2. Lennox, W. G., Gibbs, F. A., and Gibbs, E. L., The relationship in man of cerebral activity to blood flow and blood constituents. J. Neurol. and Psychiat., 1938, 1, 211.

3. Davis, P. A., Effect on the electroencephalogram of alterations of blood sugar level. Am. J. Physiol., 1941, 133, 259.

4. Hoagland, H., Rubin, M. A., and Cameron, D. E., The electroencephalogram of schizophrenics during insulin hypoglycemia and recovery. Am. J. Physiol., 1937, 120, 559.

5. Hoagland, H., Cameron, D. E., and Rubin, M. A., The delta index of the electroencephalogram in relation to insulin treatments of schizophrenia. Psychol. Rev., 1937, 1, 196.

6. Brazier, M. A. B., and Finesinger, J. E., Characteristics of the normal electroencephalogram. I. A study of the occipital cortical potentials in 500 normal adults. J. Clin. Invest., 1944, 23, 303.

7. Hoagland, H., Pacemakers of human brain waves in normals and in general paretics. Am. J. Physiol., $1936,116,604$.

8. Maddock, S., Hawkins, J. E., Jr., and Holmes, E., The inadequacy of substances of the "glucose cycle" for maintenance of normal cortical potentials during hypoglycemia produced by hepatectomy with abdominal evisceration. Am. J. Physiol., 1939, 125, 551.

9. Himwich, H. E., et al., Clinical, electroencephalographic, and biochemical changes during insulin hypoglycemia. Proc. Soc. Exper. Biol. and Med., 1939, 40, 401.

10. Himwich, H. E., Daly, C., Fazekas, J. F., and Herrlich, H., The effect of thyroid medication on brain metabolism of cretins. Am. J. Psychiat., 1942, 98, 489.

11. Lindsley, D. B., and Rubenstein, B. B., Relationship between brain potentials and some other physiological variables. Proc. Soc. Exper. Biol. and Med., 1937, 35, 558.

12. Ross, D. A., and Schwab, R. S., The cortical alpha rhythm in thyroid disorders. Endocrinology, 1939, $25,75$.

13. Gellhorn, E., and Kessler, M., The effect of hypoglycemia on the electroencephalogram at varying degrees of oxygenation of the blood. Am. J. Physiol., 1942, 136, 1. 